\title{
A importância do trabalho com a variação linguística em um primeiro ano do ciclo de alfabetização
}

\section{The importance of working with linguistic variation at a first year of literacy cycle}

\author{
Débora Tatiane Costa Rosa ${ }^{1}$ \\ Taíse Simioni $^{2}$
}

\begin{abstract}
Resumo: Este trabalho tem por objetivo apresentar os resultados de uma pesquisa-ação baseada em uma proposta de intervenção que buscou a reflexão sobre a língua oral e escrita e a discussão sobre a variação linguística envolvendo alunos do primeiro ano do ensino fundamental. Fundamenta a proposta apresentada uma discussão sobre o letramento e a alfabetização (SOARES, 1998), sobre os multiletramentos (DIAS, 2012; ROJO, 2012; TEIXEIRA; LITRON, 2012), sobre a variação linguística e, mais especificamente, a monitoração estilística (BORTONI-RICARDO, 2004; 2005). Participaram da pesquisa-ação, além da professora-pesquisadora, 20 alunos do $1^{0}$ ano do ciclo de alfabetização do ensino fundamental de uma escola pública de Bagé-RS. A proposta de intervenção foi organizada em módulos ao longo dos quais foram realizadas variadas atividades envolvendo a reflexão sobre a variação linguística. A culminância da proposta de intervenção foi o lançamento de um documentário produzido pelos alunos. O resultado da proposta de alfabetização baseada na reflexão sobre a língua oral e escrita permitiu que as crianças construíssem seu processo de escrita e leitura de forma significativa e crítica.
\end{abstract}

Palavras-chave: Alfabetização; Variação linguística; Monitoração estilística.

Abstract: This paper aims to present the results of an action research based in an intervention proposal that looked for a reflection about oral and written language and the discussion about linguistic variation involving students from a first year of elementary school. The present proposal is based in a discussion about literacy and alphabetization (SOARES, 1998), about the multi-literacy (DIAS, 2012; ROJO, 2012; TEIXEIRA; LITRON, 2012), about the linguistic variation and, more specifically, the stylistic monitoring (BORTONI-RICARDO, 2004; 2005). Besides the teacherresearcher, 20 students from a 1st year of literacy cycle of elementary school from a public school of Bagé-RS participated of the action research. The intervention proposal was organized in modules, along which varied activities were realized involving the refletion about the linguistic variation. The culmination of the intervention proposal was the release of a documentary produced by the students. The results of the proposal of literacy based in a reflection about the oral and written language allowed that the children built their process of written and reading in a significative and critical way.

Keywords: Literacy; Linguistic variation; Stylistic monitoring.

\footnotetext{
1 Possui graduação em Letras - Português e Espanhol pela Universidade da Região da Campanha (2003). Especialização em Educação Infantil pela Universidade Castelo Branco( 2004), Mestrado em Ensino de Línguas pela Universidade Federal do Pampa (2017). E-mail: deborayrosa@gmail.com 2 Possui graduação em Letras pela Universidade Federal do Rio Grande do Sul (2002), mestrado em Letras pela Universidade Federal do Rio Grande do Sul (2005) e doutorado em Letras pela Universidade Federal do Rio Grande do Sul (2011). Atualmente é Professora Adjunta na Universidade Federal do Pampa. E-mail: taisesimioni@unipampa.edu.br
} 


\section{Introdução}

Este trabalho tem como tema a importância da reflexão sobre a variação linguística desde os primeiros anos da vida escolar dos alunos ${ }^{3}$. Nele, pretende-se, então, evidenciar a relevância da variação linguística desde o ciclo de alfabetização. O objetivo principal do trabalho é socializar o resultado de uma pesquisa-ação realizada com uma turma do primeiro ano do ciclo de alfabetização. Iniciamos a proposta de intervenção com a busca dos conhecimentos prévios dos alunos e através deles desenvolvemos atividades pautadas na variação linguística e na reflexão sobre a língua oral e escrita. Durante a construção de um documentário, que foi a culminância da proposta e teve como tema a história da escola onde os alunos estudavam, conseguimos trabalhar com a língua oral e escrita e com a variação que lhe é inerente. Assim, os alunos iam compreendendo a monitoração na fala e na escrita e qual é o seu papel na sociedade.

A proposta de um trabalho a partir da reflexão sobre a língua e sua importância social pode ser encontrada nos Parâmetros Curriculares Nacionais (PCNs) de Língua Portuguesa, que apresentam como um dos objetivos de língua portuguesa a serem atingidos no primeiro ciclo o seguinte:

Utilizar a linguagem oral com eficácia, sabendo adequá-la a intenções e situações comunicativas que requeiram conversar num grupo, expressar sentimentos e opiniões, defender pontos de vista, relatar acontecimentos, expor sobre temas estudados (BRASIL, 1997, p. 68).

Segundo os PCNs de Língua Portuguesa, nos primeiros anos de escolaridade, os alunos precisam saber adequar a linguagem oral a intenções comunicativas. Para tal, é necessário que reflitam sobre o que é a adequação linguística. Nesse sentido, nos primeiros anos de alfabetização, é necessário trabalhar com a reflexão sobre a língua oral e escrita e como ela se apresenta conforme as situações de uso. Assim, ao discutirmos com os alunos a maneira como nos comunicamos em casa, na escola e em outros ambientes, evidenciamos a variação linguística e a monitoração.

A próxima seção deste artigo se dedica a apresentar a fundamentação teórica do trabalho, na qual discutimos conceitos essenciais como alfabetização, letramento, multiletramentos, variação linguística e monitoração estilística. Na terceira seção, é descrita a metodologia, de maneira a mostrar o contexto em que foi desenvolvida a pesquisa-ação e como se deram as etapas de planejamento, implementação e análise da proposta de intervenção aqui discutida. A quarta seção apresenta e discute os resultados obtidos. Por fim, a quinta seção traz as considerações finais.

\section{Fundamentação teórica}

Nesta seção, que está dividida em duas partes, discutimos inicialmente algumas questões importantes sobre a alfabetização, o letramento e os multiletramentos. Na segunda parte, refletimos sobre a variação linguística e sobre a importância da sua discussão já no primeiro ano do ciclo de alfabetização.

\section{Relações entre a alfabetização, o letramento e os multiletramentos no ciclo de alfabetização}

\footnotetext{
3 Este trabalho faz parte da dissertação de Rosa (2017), desenvolvida no Mestrado Profissional em Ensino de Línguas, da Universidade Federal do Pampa.
} 
O termo "letramento" originalmente é da língua inglesa, literacy, que significa "o estado ou condição que assume aquele que aprende a ler e a escrever" (SOARES, 1998, p. 17). Essa condição não pertence unicamente aos indivíduos que aprendem a ler e a escrever, pois alguns podem não saber ler, mas sabem se posicionar frente às mais variadas situações de comunicação. Conforme Soares (1998):

Alfabetizado é aquele indivíduo que sabe ler e escrever; já o indivíduo letrado, o indivíduo que vive em estado de letramento, é não só aquele que sabe ler e escrever, mas aquele que usa socialmente a leitura e a escrita, pratica a leitura e a escrita, responde adequadamente às demandas sociais de leitura e de escrita (SOARES, 1998, p. 40).

Para Soares (1998), o letramento vai além de entender a função social da escrita, pois implica no ato de ter o hábito da leitura e, ao mesmo tempo, o prazer em ler, objetivos que não são contemplados na alfabetização, isoladamente, pois a alfabetização se estabelece no processo de codificar e decodificar palavras. 0 letramento precisa ser concebido como parte do processo de alfabetização, pois parece que, quando ambos são trabalhados simultaneamente, os alunos conseguem ampliar sua percepção e compreensão sobre a leitura e a escrita.

Quando abordamos o letramento, nesse trabalho, não podemos deixar de falar dos multiletramentos. Segundo Rojo (2012), o termo "multiletramentos" surgiu no intuito de englobar as discussões referentes às novas pedagogias do letramento e se difere do conceito de letramentos múltiplos, por este se referir à multiplicidade $\mathrm{e}$ variedade das práticas letradas da nossa sociedade e aquele fazer referência tanto à multiplicidade cultural quanto à multiplicidade de linguagens na constituição dos textos.

Para entendermos a complexidade da ampliação do conceito de letramento em multiletramentos, trazemos a afirmação de Rojo (2012) segundo a qual:

Diferentemente do conceito de letramentos (múltiplos), que não faz senão apontar para a multiplicidade e variedade das práticas letradas, valorizadas ou não nas sociedades em geral, o conceito de multiletramentos - é bom enfatizar - aponta para dois tipos específicos e importantes de multiplicidade presentes em nossas sociedades, principalmente urbanas, na contemporaneidade: a multiplicidade cultural das populações e a multiplicidade semiótica de constituição dos textos por meio dos quais ela se informa e se comunica (ROJO, 2012, p. 13).

Vivemos em um momento de avanços tecnológicos onde temos acesso a culturas de diversos locais e temos a oportunidade de mostrar a nossa. É comum nas sociedades urbanas recebermos vídeos contendo as mais variadas formas de comunicação, pois não são raras as produções que utilizam imagens, cores e sons para chamar nossa atenção para algum produto novo ou para a divulgação de alguma ideia. A comunicação passou a ser plural e as crianças que chegam ao primeiro ano do ciclo de alfabetização já conhecem tal comunicação plural, como em grupos familiares no Whatsapp, como algo importante e a partir dessa experiência descobrem que a escrita tem uma função social e que ela serve para alguma coisa.

Para reforçar a ideia de que que há necessidade de trabalharmos com os letramentos e os multiletramentos, Teixeira e Litron (2012) acrescentam:

No plano da teoria, pelos corredores da escola, muito já se ouve falar em "letramento", "desenvolvimento dos processos de escrita" e "capacidades de leitura". Na prática docente, porém, os conceitos de letramento e alfabetismo ainda se confundem, e as concepções presentes no cotidiano da sala de aula e em certos materiais didáticos também se misturam constantemente. Um desafio: transformar o discurso recorrente de professores e gestores escolares sobre a importância do letramento em práticas e concepções efetivas em sala de aula (TEIXEIRA; LITRON, 2012, p. 167-168). 
Conforme Dias (2012, p. 96), "os multiletramentos preparam os alunos para situações de interação em que sejam necessárias posturas mais contemporâneas de leitura e escrita, mais especificamente situações que envolvam o estudo da língua e o estudo dos gêneros". Entender que os alunos estão envolvidos em práticas letradas que se relacionam com a multiculturalidade e que se apresentam de forma multimodal pode transformar as aulas de língua portuguesa em um ambiente de discussões sobre a língua como representação da cultura, e não mais como um conteúdo a ser transmitido e aprendido para se responder questões em avaliações.

Compreender que trabalhar com multiletramentos é propor atividades que se dedicam aos vários níveis de uso da língua que estão presentes nas salas de aulas é perceber que as turmas não são homogêneas, mas são ricas em diversidades sociais e culturais que precisam ser observadas e discutidas durante as aulas, não só nas aulas de língua portuguesa, mas em todas as disciplinas para que os alunos aprendam a expor suas ideias e respeitem as dos outros.

Assim, a proposta aqui apresentada buscou o que Rojo (2012) chama de "alfabetismos necessários às práticas de multiletramentos"; para serem profícuos, eles precisam se direcionar "para as possibilidades práticas de que os alunos se transformem em criadores de sentidos" (ROJO, 2012, p. 29). Para o ensino que se entende como crítico e transformador, é necessário que os alunos não fiquem passivos e receptivos. Nessa perspectiva, o trabalho com os recursos linguísticos de que o falante dispõe para criar sentidos é essencial. É disso que tratamos na próxima seção.

\section{Por que trabalhar variação linguística no primeiro ano do ciclo de alfabetização}

Segundo os PCNs, "a língua é um sistema de signos históricos e social que possibilita o homem significar o mundo e a realidade" (BRASIL, 1997, p. 22). A língua tem um papel importante na sociedade pois está presente em todas as esferas sociais e através dela conseguimos ressignificar quem somos.

Ao abordarmos a questão social da língua, começamos a compreender como devemos trabalhar a variação linguística dentro da escola. É importante salientarmos a variação e a monitoração linguística para que os alunos, desde o ciclo de alfabetização, possam entender a variação linguística existente na sociedade e a importância de sabermos monitorar a fala e a escrita. Para Bortoni-Ricardo (2005):

\footnotetext{
A escola não pode ignorar as diferenças sociolinguísticas. Os professores e, por meio deles, os alunos têm que estar bem conscientes de que existem duas ou mais maneiras de dizer a mesma coisa. E mais, que essas formas alternativas servem a propósitos comunicativos distintos e são recebidas de maneira diferenciada pela sociedade (BORTONI-RICARDO, 2005, p. 15).
}

É extremamente importante que os professores tenham essa compreensão das diferenças sociolinguísticas e saibam trabalhar com os alunos a partir de questões ligadas à variação linguística. Na escola, as diferenças se encontram e se multiplicam, porém parece que nas aulas de língua portuguesa ainda trabalhamos conteúdos ligados a uma gramática tradicional, que muitas vezes pode ser bastante distante da realidade dos alunos. Por essa razão é preciso trabalhar a variação e as maneiras diferentes que usamos para dizer algo. 
Nesse sentido, o trabalho com a variação linguística deve ser o foco da reflexão sobre a língua e como ela se apresenta de várias formas em contextos diferentes. Para ressaltar a importância do trabalho reflexivo sobre a língua, citamos novamente os PCNs:

O domínio da língua tem estreita relação com a possibilidade de plena participação social efetiva, pois é por meio dela que o homem se comunica, tem acesso à informação, expressa e defende pontos de vista, partilha ou constrói visões de mundo, produz conhecimento. Assim um projeto educativo comprometido com a democratização social e cultural atribui à escola a responsabilidade de garantir a todos os seus alunos o acesso aos saberes linguísticos necessários para o exercício da cidadania, direito inalienável de todos (BRASIL, 1997, p. 21).

A escola, por ser o espaço onde os sujeitos se encontram e o local onde se aprende, precisa aprender a trabalhar com o que os alunos sabem, com aquilo que thes é comum, sem que haja discriminação com relação ao uso não prestigiado da língua. A escola, por ter esse papel social muito forte, tem a função de ampliar os saberes comunicativos dos alunos para que eles possam entender que o que nos leva a monitorar a fala e a escrita depende de fatores como o ambiente, o interlocutor e o tópico da conversa, como nos ensina Bortoni-Ricardo (2004).

Segundo Bortoni-Ricardo (2004, p. 63), "a variação ao longo do contínuo de monitoração estilística tem, portanto, uma função muito importante de situar a interação dentro de uma moldura ou enquadre". Ao sabermos os fatores que nos levam a monitorar a fala e a escrita, passamos a entender como os professores podem trabalhar com os alunos que chegam à escola com a variedade que usam em seu convívio social. Esta variedade precisa ser discutida, mas não julgada ou enquadrada como errada ou inadequada.

Na proposta que apresentamos aqui, a intenção era a de que os próprios alunos construíssem seu conceito de monitoramento, sem que este fosse imposto, mas de um jeito que notassem que, dependendo do lugar e do que se quer dizer e para quem, precisamos monitorar, elaborar, buscar a melhor forma de usar a língua e a melhor maneira de dizer o que se quer, para que a forma como nos comunicamos não permita que os outros se sintam no direito de menosprezar nossas ideias porque não nos adequamos às expectativas de determinado evento comunicativo.

\section{Metodologia}

A pesquisa-ação se estrutura na formulação de hipóteses, na comprovação, na inferência sobre problemas reais que não se estabelecem apenas a partir de dados estatísticos. Através da pesquisa-ação, é possível vincular o raciocínio hipotético e as experiências de comprovação, pois a argumentação dos pesquisadores e dos participantes tem uma função na pesquisa, necessária à interpretação da realidade observada para que se possam elaborar as ações transformadoras que constituem o objetivo maior desse tipo de pesquisa. Para Tripp (2005),

A pesquisa-ação educacional é principalmente uma estratégia para o desenvolvimento de professores e pesquisadores de modo que eles possam utilizar suas pesquisas para aprimorar seu ensino e, em decorrência, o aprendizado de seus alunos (TRIPP, 2005, p. 445).

Ao verificar-se a ação por parte dos envolvidos na pesquisa, pessoas ou grupos implicados, qualifica-se a pesquisa como pesquisa-ação por essa apresentar uma problemática que merece uma investigação, uma 
observação que possa ser conduzida pelos pesquisadores que desempenham um papel ativo durante o acompanhamento, a avaliação, a apresentação do problema e a possível solução. A solução precisa resolver ou esclarecer o problema apresentado durante o processo. Essa solução também pode ser utilizada por outros grupos que entendam que ela contempla conflitos semelhantes.

Essa pesquisa não é restrita apenas a observar um problema e elaborar possíveis soluções, senão proporcionar aos participantes, tanto os pesquisadores quanto os demais envolvidos, um desenvolvimento da emancipação do conhecimento sobre o vivenciado. É possível elaborar uma reflexão sobre o contexto em que a pesquisa se insere, pois, com conhecimento, se conduz com eficácia a metodologia que irá determinar a solução que se busca para conscientizar os envolvidos. As pesquisas-ação nem sempre chegam a apresentar conhecimentos novos sobre o que se buscou com ela, porém, para Bortoni-Ricardo (2008),

O docente que consegue associar o trabalho de pesquisa a seu fazer pedagógico, tornando-se um professor pesquisador de sua própria prática ou das práticas pedagógicas com as quais convive, estará no caminho de aperfeiçoar-se profissionalmente, desenvolvendo uma melhor compreensão de suas ações como mediador de conhecimentos e de seu processo interacional com os educandos. Vai também ter uma melhor compreensão do processo de ensino e de aprendizagem (BORTONI-RICARDO, 2008, p. 32-33).

Sabe-se que o professor precisa ser e se entender como um mediador do conhecimento, pois ele não pode se identificar como transmissor de conhecimentos prontos que não permitem a participação e a reflexão dos alunos. Dessa forma, é importante que o professor se perceba como um pesquisador das situações que ocorrem na sua sala de aula e na escola, de forma geral, pois, ao observar os acontecimentos cotidianos, o professor poderá buscar meios para mediar o processo de construção do conhecimento.

É importante salientar que a proposta de intervenção aqui apresentada, envolvendo o gênero documentário, permitiu, através de módulos, a reflexão sobre a língua e o entendimento sobre a variação linguística. Sabe-se que a variação linguística não deve ser entendida como uma atividade isolada em um capítulo do livro didático. É preciso que os professores dediquem parte do planejamento de suas aulas à reflexão sobre a língua, sobre como os alunos a utilizam e como podemos monitorá-la se quisermos. Assim, o entendimento sobre a língua será construído desde o $1^{\circ}$ ano do ciclo de alfabetização, pois o aluno precisa entender que a linguagem não é homogênea e que a sua linguagem deve ser compreendida, pois ela é a representação da sua própria identidade.

A intervenção aqui discutida, que se caracteriza como uma pesquisa-ação, foi aplicada entre os meses de maio e agosto de 2017, em uma turma de $1^{\circ}$ ano do ciclo de alfabetização, de uma escola da Rede Pública Municipal de Bagé-RS. Essa escola é central e recebe alunos do centro, de outros bairros mais distantes e também da zona rural. A turma era composta por 20 alunos, 13 meninos e 7 meninas, com idades entre seis e sete anos. Esses alunos já frequentavam a escola desde a pré-escola e, por essa razão, conheciam todos os espaços que compõem o ambiente físico e também os profissionais que trabalham nesse local. A primeira autora deste artigo atuou, em sala de aula, como professora pesquisadora de sua própria prática docente. Cabe destacarmos que, antes de iniciarmos a intervenção, os pais dos alunos assinaram um termo de consentimento, que autorizava a participação dos alunos na pesquisa.

Como forma de registro das atividades, foram utilizadas gravações em áudio e vídeo, além de registro escrito em diário descritivo. Os áudios eram realizados durante a aplicação das atividades para registrar a participação dos alunos e também a forma como o trabalho era conduzido pela professora-pesquisadora. 
Para analisar o desenvolvimento dos conhecimentos dos alunos no decorrer das atividades, foi utilizado um caderno de produção. Todos os alunos receberam um caderno, onde as atividades eram registradas. Esse material era recolhido, analisado e entregue aos alunos antes do início de cada atividade. Posteriormente o material dos cadernos foi digitalizado. A análise apresentada na próxima seção buscou, principalmente nos áudios, momentos de reflexão sobre a língua oral e escrita.

Quanto à proposta de intervenção, ela foi organizada em módulos. O primeiro módulo ("Documentário: o que é?") buscou conhecer o gênero documentário a partir dos conhecimentos prévios dos alunos. As atividades propostas buscavam conhecer o que os alunos sabiam e como eles ampliaram esse conhecimento. No segundo módulo ("Documentário: como se faz?"), investigamos o gênero, refletimos sobre ele e organizamos um roteiro contendo o que faríamos para produzir um documentário. O terceiro módulo ("Documentário: uma representação da história") foi dedicado à pesquisa, a entrevistas, ao resgate da memória da comunidade escolar. O quarto módulo ("Documentário: quase um quebra-cabeça") tratou das questões ligadas à pré-edição, à edição, à decupagem e à edição final. No quinto módulo ("Documentário: uma construção coletiva"), buscamos a opinião de uma turma de alunos que conhecia a história da nossa escola e das escolas que formaram a nossa, para que juntos pudéssemos verificar se a primeira versão era um registro da realidade. O sexto e último módulo ("Documentário: Vem ver!") organizou a divulgação do evento de lançamento do documentário. ${ }^{4}$

Durante a realização dos módulos, os alunos tiveram a oportunidade de reconhecer o gênero documentário, produzir roteiros, enviar e-mails, produzir perguntas, entrevistar, reavaliar o roteiro inicial, organizar o documentário, produzir trilha sonora, editar o documentário e apresentá-lo à comunidade escolar.

\section{Análise e discussão sobre a implementação da proposta de intervenção}

Na análise aqui apresentada, que é um recorte de Rosa (2017), o foco serão os momentos em que se apresentou, de maneira mais explícita, uma discussão sobre a variação linguística e, mais especificamente, sobre a monitoração linguística. Não temos, portanto, a intenção de apresentar todas as atividades de todos os módulos.

No primeiro módulo, após algumas atividades envolvendo o gênero documentário, os alunos foram questionados sobre quem poderia auxiliar o grupo na realização do documentário sobre a escola. A professorapesquisadora sugeriu, nesse momento, o contato via e-mail e mostrou aos alunos duas mensagens eletrônicas com graus de intimidade diferentes. O Quadro 1 mostra parte do diálogo desenvolvido nesse momento.

Quadro 1 - Diálogo sobre o gênero e-mail

Professora: Os e-mails são iguais ou diferentes?

Aluno: São diferentes?

Professora: Quem recebeu o primeiro e-mail? Para quem era o segundo e-mail? Pensem comigo: o que tem no primeiro email? E como é o segundo? Qual é a diferença entre os dois?

Aluna: O primeiro para uma amiga e o outro para uma professora.

Professora: Qual é a diferença nas mensagens enviadas? Como iniciei a mensagem?

Aluno: Uma começa com "Oi", a outra com "Bom dia!".

Professora: Quando falamos com um amigo e quando falamos com outras pessoas a nossa fala muda?

Alunos: Muda!

Professora: Vocês conseguem perceber isso? Quando vocês falam comigo e quando falam com a diretora a maneira de falar muda?

Alguns alunos: Sim. 
Professora: Vocês conseguem dizer por que isso acontece?

Alguns alunos: Porque ela não nos conhece!

Professora: Ela conhece, mas não tem a mesma relação de intimidade, assim como nos e-mails que mostrei. Com a minha amiga usei um "oi" e para minha professora "Boa tarde!".

Como pode ser visto no Quadro 1, refletimos sobre a maneira como foram escritos os e-mails e os alunos deram suas contribuições sobre como eles também se comunicam de maneira diferente conforme 0 envolvimento deles com as pessoas. Para ressignificar o que os alunos perceberam, conversamos sobre como eles se comunicam com a diretora e com a professora e sobre como eles cuidam a maneira de falar com essas pessoas. A partir da atividade de análise do gênero e-mail, conseguimos, conforme Bortoni-Ricardo (2004), criar condições para que os alunos refletissem sobre sua competência comunicativa, para que pudessem usar com segurança os mais variados recursos comunicativos.

A professora-pesquisadora propôs, então, a escrita de um e-mail para uma jornalista, com o objetivo de solicitar uma ajuda profissional para que se pudesse compreender a estrutura do gênero documentário. Com o auxílio dos alunos, começamos a conversar sobre como nos comunicaríamos com alguém que não nos conhecia. É importante notar que os alunos conseguiram produzir o texto de maneira coletiva, observando as características do gênero, e perceberam a monitoração de forma reflexiva e dialogada.

Através das atividades propostas ao longo do primeiro módulo da intervenção, de que fornecemos um exemplo acima, conseguimos ampliar o conhecimento dos alunos com relação ao entendimento da função social da escrita, da percepção da variação e da monitoração da fala e da escrita, conforme nosso grau de envolvimento com as pessoas que participam da interação.

Na última atividade do segundo módulo, houve uma conversa a respeito de duas entrevistas que haviam sido concedidas pelos alunos e pela professora-pesquisadora sobre o projeto que estava sendo desenvolvido. Nesse momento foi importante identificar a postura dos alunos que foram a uma rádio local e dos alunos que foram entrevistados na escola para um jornal impresso local.

Os alunos conseguiram identificar a organização dos jornais e puderam esclarecer a diferença que existe entre os jornais escritos e os jornais orais, pois o tema da entrevista era o mesmo, mas a forma de apresentação dos dois era diferente. Na rádio as perguntas eram respondidas no exato momento em que eram feitas e no jornal escrito a repórter havia organizado o texto conforme as respostas dos alunos. Conversamos sobre o porquê de cuidarmos a maneira como falamos, pois não conhecíamos as pessoas que ouvem o jornal, mas, quando fomos entrevistados pelo jornal impresso, falamos com a repórter e cuidamos um pouco menos da fala, pois estávamos no ambiente da escola.

É importante notar que os alunos, após a leitura da reportagem sobre o documentário, apresentada no jornal impresso local, conseguiram novamente perceber a função social da escrita. Ao participarmos da entrevista na rádio local, o que conversamos nas aulas sobre a variação linguística e sobre a monitoração passou a ter um significado mais claro e prático, pois os alunos falariam com alguém que eles não conheciam. Não se tratava apenas da entrevistadora, mas do público que acompanha a programação da rádio.

Percebemos que os alunos cuidaram a forma de se comunicar, pois, antes de a entrevista começar, a entrevistadora fez várias perguntas e explicou: "quando ligar a luz naquela janelinha, começamos a gravar". A partir daquele momento, notamos a postura e a preocupação dos alunos em dar as informações sobre o documentário.

No terceiro módulo, como parte das atividades de busca de informações sobre a escola para a construção do documentário, conversou-se sobre as duas antigas escolas que haviam se unido para dar origem à 
atual escola onde os alunos estudavam. Quando começamos a pesquisa, os alunos observaram que a estrutura dos prédios das antigas escolas sofreu alterações. A partir dessa observação das mudanças, provocadas ao longo do tempo, conversamos sobre a linguagem e se eles notavam diferença entre a forma como as pessoas falam. Alguns alunos não percebiam, porém, os alunos que conviviam com pessoas de idades muito diferentes conseguiam perceber que a língua se altera conforme a idade das pessoas.

Ao realizarmos a pesquisa, notamos que o registro escrito do material pesquisado mudou bastante. No material da pesquisa havia convites, boletins e históricos escolares, que atualmente são feitos de outra forma, como os históricos escolares que atualmente são digitados e têm outro formato. Além disso, nos dias atuais os alunos do ciclo de alfabetização não recebem boletins e sim pareceres. Continuamos conversando sobre essas mudanças e a relação disso com mudanças na língua, quando os alunos olharam o material escrito e registros fotográficos deixados pelas antigas escolas. Os alunos notaram o papel, a letra, os carros e as roupas. Partindo dessas observações, novamente buscamos dialogar sobre a língua e se eles notam diferença entre a fala deles e a dos pais.

Como parte do quarto módulo, foram feitas atividades relativas à trilha sonora do documentário. Na escola havia uma estagiária do Curso de Música da UNIPAMPA, chamada Thais Sauco. Conversamos e resolvemos solicitar seu auxílio. Nesse momento, para entrar em contato com a estagiária, utilizamos um aplicativo do celular. O Quadro 2, a seguir, apresenta a construção da mensagem enviada.

Quadro 2 - Mensagem no WhatsApp

Professora: Como mandaremos a mensagem? Nós já a conhecemos e usaremos o celular de quem é amigo dela. Então como será nossa mensagem com "Boa tarde, Professora Thais" ou "Oi, Thais"? O que vocês acham?

Alunos: "Oi, Thais. Como estás?"

Professora: Então, se a pessoa é minha amiga posso usar um "oi", mas, se não for, devo começar a mensagem com "Boa Tarde!". Como escrevo para minha amiga Thais:

"Oi, Thais

Preciso da tua ajuda para produzir a trilha sonora do documentário. Quando tu podes vir na escola?

Beijo, espero tua resposta."

Alunos: Assim, tia. Ficou bem!

Nessa proposta conseguimos perceber novamente que os alunos do primeiro ano conseguiram compreender que temos formas diferentes para nos comunicar, pois, se conhecemos ou se não conhecemos uma pessoa, usamos diferentes recursos.

No sexto e último módulo, organizamos o evento da apresentação do documentário para a comunidade. Combinamos a divulgação do evento em jornais, telejornais e elaboramos convites para autoridades. $\mathrm{Na}$ secretaria da escola, a secretária explicou para os alunos como são os e-mails que a escola envia quando deseja convidar a Secretaria Municipal de Educação, outras secretarias e o prefeito para um evento dentro da escola. Após conversarmos com a secretária, combinamos com ela a mensagem que enviaríamos para as secretarias. Os alunos entenderam que esse e-mail era mais elaborado, havia uma série de palavras que eles não conheciam, como, por exemplo, "Ilmo.", mas que precisavam estar no texto. Nessa atividade, os alunos, ao conversarem com a secretária da escola, puderam notar que alguns registros escritos seguem um modelo, pois são utilizados com o mesmo propósito.

$\mathrm{Na}$ noite de lançamento do documentário, seguimos o roteiro que havíamos acordado e, com consciência, os alunos sabiam monitorar a fala na recepção e também na apresentação do documentário. Para começar o evento no refeitório da escola, os alunos apresentaram o documentário cumprimentando os presentes, 
informando o objetivo do documentário, apresentando as formas de produção e agradecendo a todos. No segundo momento, assistimos ao documentário.

Para finalizar o evento e para que os alunos tivessem mais uma vez um momento de mostrar que eles eram os protagonistas do seu aprendizado, eles abriram a roda de conversa onde os presentes tiveram a oportunidade de fazer perguntas e elogiar o trabalho dos alunos.

\section{Considerações finais}

No trabalho proposto aos 20 alunos de um primeiro ano do ciclo de alfabetização, notamos que, ao buscarmos o que os alunos sabiam e ao compreendermos a forma como eles falavam sobre suas experiências, começamos a valorizar aquilo que faz parte do cotidiano dos alunos. Ao trabalharmos com a variação linguística e a reflexão sobre a língua, notamos que os alunos passaram a compreender que a língua varia e que com ela nos comunicamos e interagimos com os outros e com o mundo. A proposta, de uma forma bastante particular, proporcionou aos alunos algo que nos parece ser real, pois não criamos textos fora da realidade ou textos que seriam lidos pela professora ou para a turma; os alunos criaram textos para uma comunidade escolar, eles tinham uma função social que era claramente reconhecível e reconhecida pelos alunos.

Através dos módulos, íamos refletindo sobre a forma como nos comunicamos e como podemos monitorar nossa comunicação. Com as conversas sobre a produção do documentário, passamos a trabalhar com algo real que nos possibilitava a construção do conhecimento com relação à língua oral e escrita e os alunos iam avançando em seu conhecimento sobre a língua.

Os alunos do $1^{\circ}$ ano não tinham vergonha de falar sobre o documentário, sabiam colocar suas ideias e tinham consciência da monitoração conforme o local, o tópico e o interlocutor. Conseguimos constatar a monitoração dos alunos pois, ao falarem com outros alunos durante a elaboração do documentário, tinham uma forma de comunicação e ao irem a um programa de rádio, por exemplo, os alunos tinham outra maneira de se comunicar, buscando sempre a mais adequada.

Ao concluirmos a produção do documentário, tínhamos uma turma de alunos que dialogava com fluência e liberdade de escolhas, lia e produzia com consciência sobre a função social da língua.

\section{Referências}

BORTONI-RICARDO, Stella Maris. Educação em língua materna: a sociolinguística na sala de aula. São Paulo: Parábola, 2004.

BORTONI-RICARDO, Stella Maris. Nós cheguemu na escola, e agora? Sociolinguística e educação. São Paulo: Parábola, 2005.

BORTONI-RICARDO, Stella Maris. O professor pesquisador: introdução à pesquisa qualitativa. São Paulo: Parábola, 2008.

BRASIL. Ministério da Educação e do Desporto. Secretaria de Educação Fundamental. Parâmetros curriculares nacionais. Língua Portuguesa: Ensino da primeira à quarta série. Brasília, DF: MEC/SEF, 1997.

DIAS, Anair V. Martins. Hipercontos multissemióticos: para a promoção dos multiletramentos In: ROJO, Roxane; MOURA, Eduardo (orgs.) Multiletrametos na escola. São Paulo: Parábola, 2012. p. 95-122.

ROJO, Roxane. Pedagogia dos multiletramentos: diversidade cultural e de linguagens na escola. In: ROJO, Roxane; MOURA, Eduardo (orgs.) Multiletrametos na escola. São Paulo: Parábola, 2012. p. 11-31. 
ROSA, Débora Tatiane Costa. Documentário: uma proposta que contempla o letramento e a variação linguística para a formação de cidadãos críticos desde o $1^{\circ}$ ano do ciclo de alfabetização. 2017. 123f. Dissertação (Mestrado em Ensino de Línguas) - Universidade Federal do Pampa. Bagé, 2017.

SOARES, Magda. Letramento: um tema em três gêneros. Belo Horizonte: Autêntica/ CEALE, 1998.

TEIXEIRA, Adriana; LITRON, Fernanda. O manguebeat nas aulas de Português: videoclipe e movimento cultural em rede. In: ROJO, Roxane; MOURA, Eduardo (orgs.) Multiletrametos na escola. São Paulo: Parábola, 2012. p. 167-180.

TRIPP, David. Pesquisa-ação: uma introdução metodológica. Educação e Pesquisa, v. 31, n. 3, p. 443-466, 2005. 